\title{
Microstructure and Properties of the Ti6Al4V/Inconel 625 Bimetal Obtained by Explosive Joining
}

\author{
Krzysztof Topolski, Zygmunt Szulc, and Halina Garbacz
}

\author{
(Submitted November 10, 2015; in revised form April 13, 2016; published online April 29, 2016)
}

\begin{abstract}
The study is concerned with the bimetallic plate composed of the Ti6Al4V and Inconel 625 alloys. The alloys were joined together using the explosive method with the aim to produce a bimetallic joint. The structure and the mechanical properties of the as-received raw Ti6Al4V and Inconel 625 alloys, the Ti6Al4V/Inconel 625 joint, and the joint after annealing $\left(600{ }^{\circ} \mathrm{C}\right.$ for $\left.1 \mathrm{~h}\right)$ were examined. The samples observations were performed using a light microscope and a scanning electron microscope. The mechanical properties were estimated by microhardness measurements, tensile tests, and three-point bending tests. Moreover, the deformation strengthening of the metals and the strength of the joint were analyzed. The explosive process resulted in a good quality bimetallic joint. Both sheets were deformed plastically and the joint surface between the alloys had a wavy shape. In the area of the joint surface, the hardness was increased. For example, the annealing at $600{ }^{\circ} \mathrm{C}$ for $1 \mathrm{~h}$ resulted in changes of the microhardness in the entire volume of the samples and in changes of the morphology of the joint surface. In three-point bending tests, the samples were examined in two opposite positions (Ti6Al4V on the top or Inconel 625 on the top). The results indicated to depend on the position in which the sample was tested.
\end{abstract}

Keywords bimetal, explosive joining, Inconel, titanium alloys

\section{Introduction and Motivation}

Nowadays, in the production of component parts and final products, the industries worldwide increasingly use advanced joining methods. One of the important and constantly developed technologies of joining metals is explosive joining which utilizes local plastic deformation of the materials to be joined when subjected to high pressure (Ref 1-8).

The high-energy load acts in the pulse way and its source is the detonation of a explosive charge. The energy generated during the detonation is used for accelerating one metal (mobile, cladding metal) toward the other metal (stationary, base) so as to form a bond by solid-state joining (Ref 3 ). The joint is formed due to pressure and not heat. The explosive method is used for joining metallic materials, in particular metal sheets. Compared to other techniques used for joining metals (such as resistance welding, traditional welding), the explosive method has the fundamental advantage in that it can be used for joining dissimilar metals, whereas joining them by the traditional methods is little effective or even impossible (e.g.,

This article is an invited submission to JMEP selected from presentations at the Symposium "Joining Technologies," belonging to the Topic "Joining and Interfaces" at the European Congress and Exhibition on Advanced Materials and Processes (EUROMAT 2015), held September 20-24, 2015, in Warsaw, Poland, and has been expanded from the original presentation.

Krzysztof Topolski and Halina Garbacz, Faculty of Materials Science and Engineering, Warsaw University of Technology, Wołoska 141, 02-507 Warsaw, Poland; and Zygmunt Szulc, Z.T.W. Explomet, ul. Oświęcimska 100H, 45-641 Opole, Poland. Contact e-mails: kt.topolski@gmail.com and hgarbacz@inmat.pw.edu.pl. aluminum with steel) (Ref 1, 2, 4). Moreover, the explosive technique known as "cold welding" (Ref 7) requires no heating and melting the material, which in certain cases is very important. The explosive welding has also some disadvantages in that it enables joining only products with simple geometries (Ref 1).

Among the publications concerning explosive joining available in the literature, most is devoted to joining pure titanium with various metals (Ref $1,5,7,8)$. This would suggest that, thanks to its properties, titanium is particularly suitable to be processed by this method.

It should be however noticed that joining titanium alloys with nickel alloys by the explosive method is a new issue which has not been reported yet. In the studies reported in the literature concerning the Ti6Al4V alloy, this alloy is only joined with stainless steel (Ref 2), aluminum (Ref 4), copper (Ref 9), and low-carbon steel (Ref 10). Therefore, experiments with the Ti6Al4V alloy and the Inconel 625 alloy could be a new experience. Moreover, this is interesting from the scientific and applicative points of view.

In our earlier publication we presented the results concerning the explosive joining of pure Ti with pure Ni (Ref 11). The $\mathrm{Ti} / \mathrm{Ni}$ bimetallic sheets of this type are used in the electrolysers intended production of chlorine. The electrolysis is conducted at a relatively low temperature (below $100{ }^{\circ} \mathrm{C}$ ), but while assembling the device, the bimetallic components are subjected to welding at a temperature of about $600{ }^{\circ} \mathrm{C}$. This is why an additional research task is here for the evaluation of the heat stability of the Ti6Al4V/Inconel 625 bimetallic sheet.

In the present study, the materials to be joined were the Ti6Al4V and Inconel 625 alloys. We experimented with explosive joining these two alloys. The strength and hardness of each of these alloys are higher, and the plasticity is lower than those of the materials examined in our previous study (i.e., pure $\mathrm{Ti}$ and pure $\mathrm{Ni}$ ). It should be noticed that the technology of the Ti6Al4V/Inconel 625 joint is innovatory and constitutes a special challenge. 
The aim of this research was to determine the influence of the plastic deformation induced during the explosion on the structure and mechanical properties of the joint and to evaluate its quality. The influence of the annealing on the microstructure and mechanical properties of the explosively joined Ti6Al4V/ Inconel 625 bimetals was also investigated.

\section{Materials and Investigation Methods}

The materials examined were a titanium alloy (Ti6Al4V) and a nickel alloy (Inconel 625) with the chemical compositions given in Table 1. The as-received raw materials, the Ti6Al4V/Inconel 625 joints, and the joints after annealing were examined. During the explosive joining, the Ti6Al4V sheet with a thickness of $0.84 \mathrm{~mm}$ was the cladding material, whereas the Inconel 625 sheet with a thickness of $1.55 \mathrm{~mm}$ was the base. The surface area of the bimetal was sized at $200 \times 200 \times 2.4 \mathrm{~mm}^{3}$. The experiments with explosive joining were conducted at the Z.T.W. Explomet commercial company, Poland.

After the joining process, part of the samples was subjected to annealing at a temperature of $600^{\circ}$ for $1 \mathrm{~h}$ to simulate the real exploitation conditions.

The samples were examined by light microscopy and scanning electron microscopy Hitachi 3500 equipped with Energy Dispersive Spectrometry (EDS) attachment.

The mechanical properties were determined using microhardness measurements, tensile test, and three-point bending tests. The microhardness was measured by the Vickers method under a load of $200 \mathrm{~g}$. The tensile tests were conducted according to Standard PN-91 H-04310 using standard flat samples (dumbbell shape, Fig. 10). The vertical MTS 858 universal hydraulic testing machine was applied. The cross section surface area of the test samples was about $24 \mathrm{~mm}^{2}$ $\left(2.4 \times 10 \mathrm{~mm}^{2}\right)$ and the original gage length of the samples $\left(l_{0}\right)$ was $18 \mathrm{~mm}$. Total length of these samples was $95 \mathrm{~mm}$. Before the tests, the side surfaces and sharp edges of the samples were ground. The three-point bending tests were conducted in a QTest strength machine in accordance with the Standard EN 910:1996 at room temperature and at the same cross-bar traverse speed of $1 \mathrm{~mm} / \mathrm{min}$. The loading force was applied from the top down. Before the tests, the side surfaces and sharp edges of the samples were ground. The samples were installed in the machine in the two positions: (1) Ti6Al4V sheet was on the top of the bimetallic sample, whereas Inconel 625 sheet was at the bottom (description: Ti6A14V-top), (2) Inconel 625 sheet was on the top of the bimetallic sample, whereas Ti6Al4V sheet was at the bottom (description: Inconel 625-top). The samples were of the flat shape with dimensions $40 \times 10 \times 2.4 \mathrm{~mm}^{3}$. In the case of tensile tests and three-point bending tests, the two samples for each condition were tested.

\section{Results and Discussion}

\subsection{Microstructure and Interface: Microscopic Observations}

The microstructures of Ti6Al4V and Inconel 625 sheets in the as-received state, intended to be joined by the explosive method are shown in Fig. 1. The microstructure of the titanium alloy was typical of the state after recrystallization. It contains equiaxial globular grains of the $\alpha$-phase with similar sizes which are surrounded with a net of the $\beta$-phase (Fig. 1a). In the nickel alloy, the microstructure contained equiaxial grains with an average equivalent grain diameter of $7.5 \mu \mathrm{m}$. It was not quite homogeneous and the grains slightly differed in size (Fig. 1b).
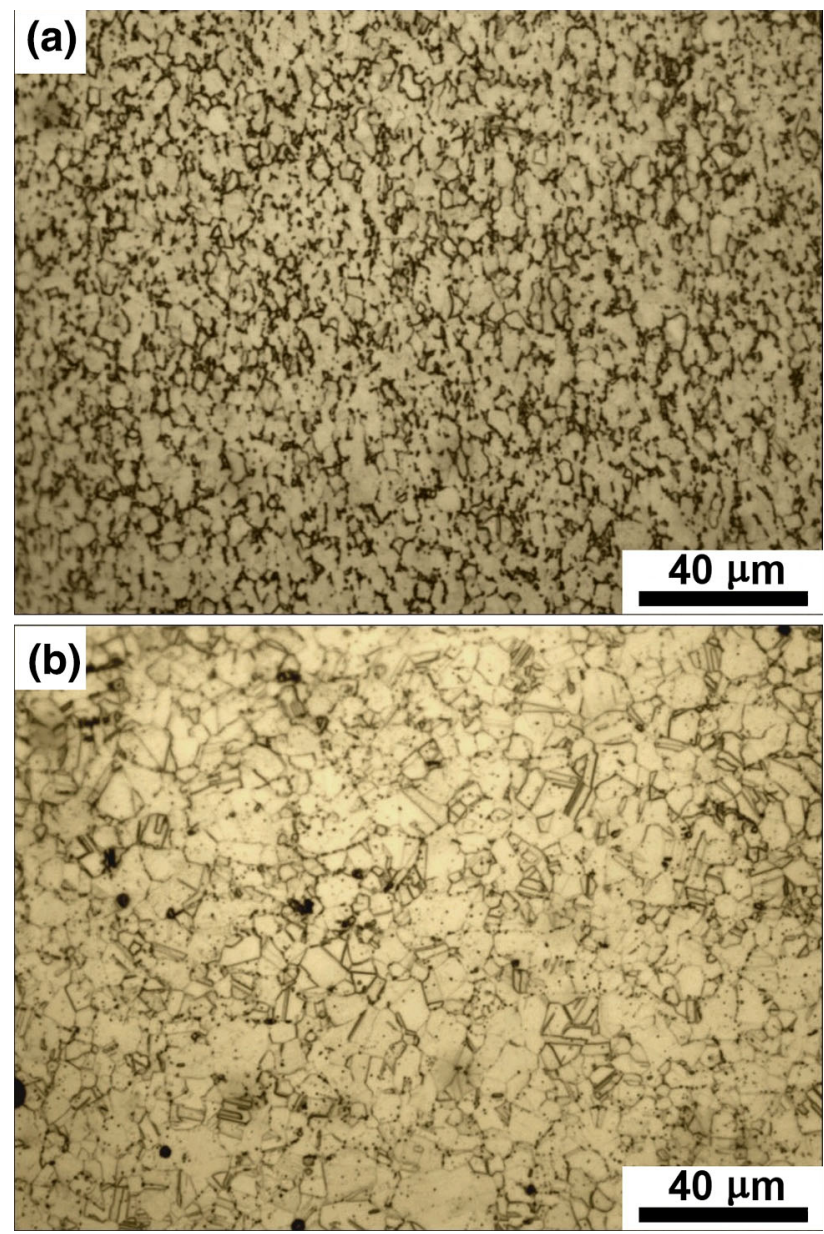

Fig. 1 Microstructures of Ti6A14V and Inconel 625 sheets in the as-received state intended to be joined by the explosive method: (a) Ti6Al4V, (b) Inconel 625, light microscopy

Table 1 Chemical composition of the metals to be joined

\begin{tabular}{lccccccccccc}
\hline \% Mass & $\mathbf{A l}$ & $\mathbf{V}$ & $\mathbf{O}$ & $\mathbf{F e}$ & $\mathbf{N}$ & $\mathbf{C}$ & $\mathbf{H}$ & $\mathbf{T}$ & $\ldots$ & \\
\hline Ti6A14V & 6.07 & 3.99 & 0.12 & 0.04 & 0.01 & 0.01 & 0.015 & $\ldots$ & $\ldots$ & Base \\
\hline \% Mass & $\mathbf{C r}$ & $\mathbf{M o}$ & $\mathbf{N b}$ & $\mathbf{F e}$ & $\mathbf{M n}$ & $\mathbf{S i}$ & $\mathbf{A l}$ & $\mathbf{T i}$ & $\mathbf{C}$ & $\mathbf{N i}$ \\
\hline Inconel 625 & 21.12 & 9.46 & 3.81 & 0.48 & 0.42 & 0.34 & 0.32 & 0.3 & 0.08 & Base \\
\hline
\end{tabular}



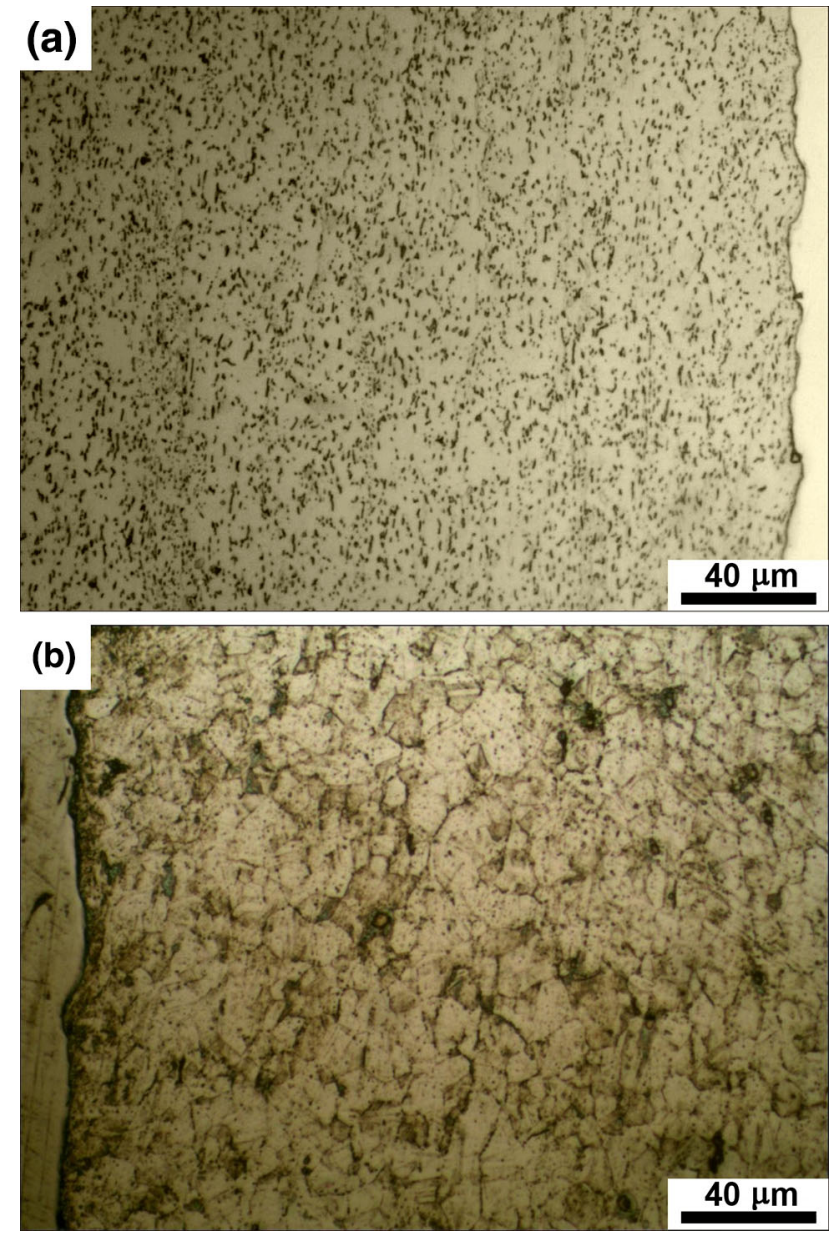

Fig. 2 The microstructures and the joint zone of the bimetallic Ti6A14V/Inconel 625 sheets joined by the explosive method: (a) Ti6Al4V, (b) Inconel 625, light microscopy

The microstructures and the joint zone of the bimetallic Ti6Al4V/Inconel 625 sheets joined by the explosive method are shown in Fig. 2. The detonation and the shock wave generated during the explosion resulted in both the Ti6Al4V and Inconel 625 sheets being deformed plastically and forming a characteristic wavy joint surface between them (Fig. 2). In general, it is just this wavy structure which is expected and desired after an explosive welding process because the area of the interface is then larger and in addition, stronger $(\operatorname{Ref} 1,5,9)$. The wave formed along the joint has an irregular shape. In the region of the joint, the structures of the two metals are distorted. This region of intensive deformation has the thickness below $10 \mu \mathrm{m}$. Beyond the region of the joint, both the Ti6Al4V and Inconel 625 structures revealed by etching were not deformed and remained unchanged (Fig. 2).

After annealing at $600{ }^{\circ} \mathrm{C}$ for $1 \mathrm{~h}$, the microstructures of the two metals are not changed. The wavy shape has been preserved. Beyond the region of the joint, the microstructures of the two metals are not changed significantly. After annealing, the average grain size of Inconel 625 slightly increased to $10 \mu \mathrm{m}$.

The joint zone of the Ti6A14V/Inconel 625 joint was also examined using a scanning electron microscope (Fig. 3, 4, 5). Via the contrast achieved, we can see different materials of the sheets and also the joint geometry. Figure 3(a) shows the joint
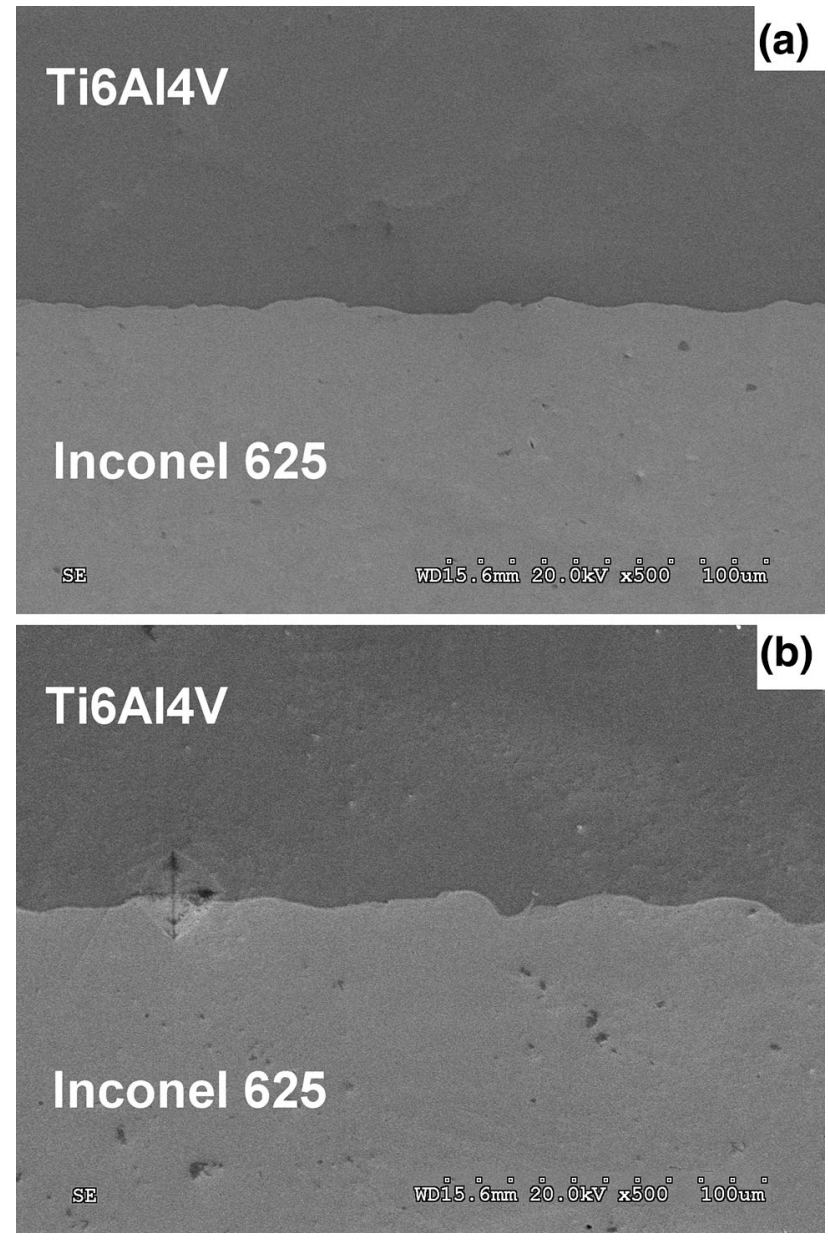

Fig. 3 The joint zone of the Ti6A14V/Inconel 625 joint examined in a scanning electron microscope: (a) joint before heat treatment, (b) joint after heat treatment

before the heat treatment (HT), and Fig. 3(b) and 4 shows it after the HT. It appears that, in general, the joint line has not been changed by the HT. But, as can be seen at higher magnification (Fig. 4a, b, in both sections of the direction of joining), the diffusion processes induced during heating resulted in the formation of a specific morphology in the contact region between the two materials.

In the case of joints, the SEM-EDS technique is also applied for the analysis of the phenomena such as diffusion and melting. In this work, for the joint before the HT, SEM-EDS results showed a sharp transition between the two materials. In the joint line, the clear change of the chemical composition was observed, similarly as in the literature (Ref 8,12 ). These results exclude the remelting of both materials in the joint line. Moreover, the diffusion between the Ti6Al4V and Inconel 625 sheets is not visible under the accuracy of SEM. In the study (Ref 12), where the Incoloy 800 alloy and the 304 stainless steel were joined, the SEM technique was also applied to investigate the possible diffusion during explosive joining. Base on these results, all elements also showed a sharp transition at the joint line. It indicates that elements diffusion during explosive welding process is not observed under the accuracy of line scanning detection (Ref 12).

In this work, for the joint after the HT, the thickness of the diffusion zone was evaluated to be maximum $2 \mu \mathrm{m}$ (Fig 4 , 

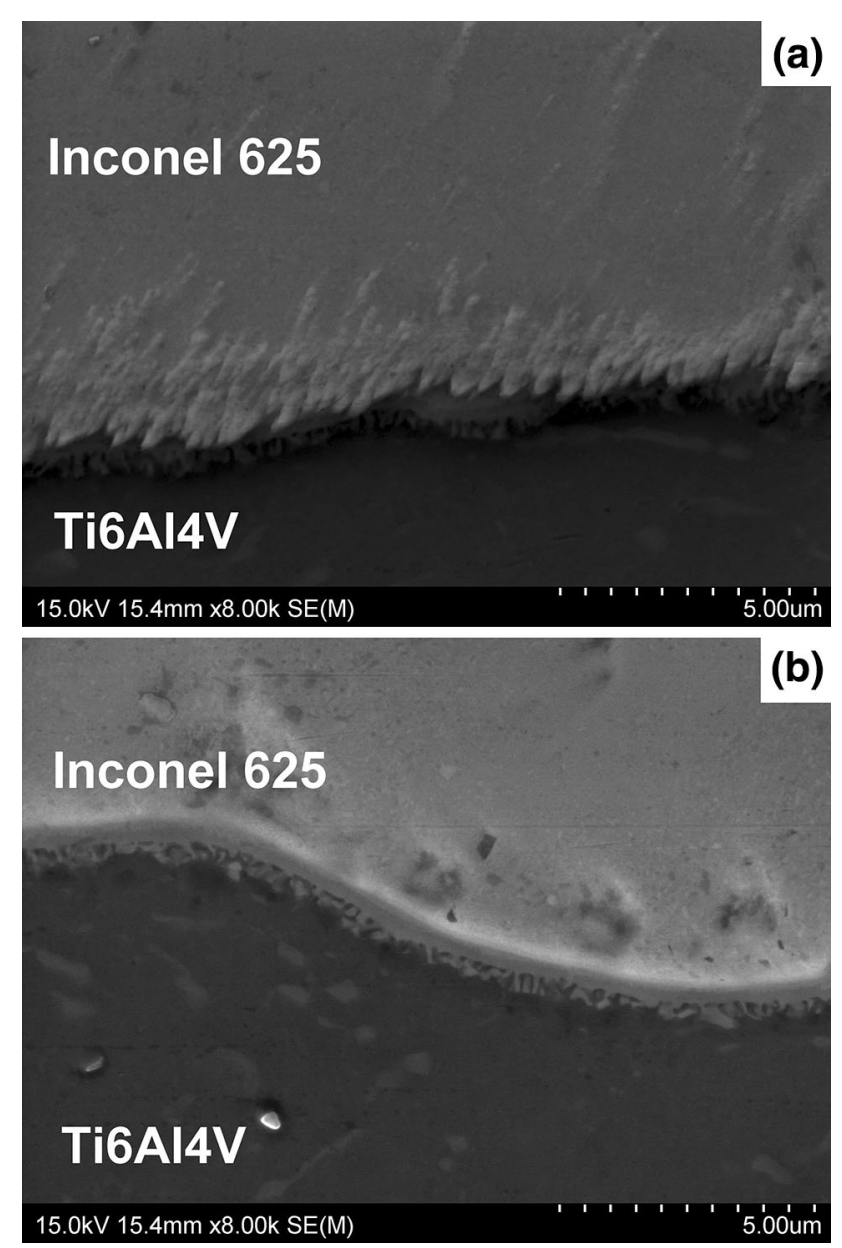

Fig. 4 The joint zone of the Ti6Al4V/Inconel 625 joint examined in a scanning electron microscope after heat treatment shown at higher magnification: (a) cross section perpendicular to the direction of joining, (b) cross section parallel to the direction of joining

5). In this case, this was probably due to the formation of a thin transition layer. From the viewpoint of this research this thin zone is insignificant and negligible. In the EDS line analysis of the elements distributions, the sudden change of the chemical composition in the joint zone is visible (Fig. 5). As in the previous sample, the EDS results also showed a sharp transition between the two materials. According to the EDS analysis, the clear change of the material can be observed, similarly, as in the case of the joint without HT. It indicates that, in this case, the elements diffusion between the Ti6A14V and Inconel 625 sheets is not visible under the accuracy of line scanning detection.

\subsection{Mechanical Properties}

The plastic deformation induced during the explosive joining process resulted in the strengthening of the bimetal at the surface between the two materials. This was confirmed by the results of the microhardness measurements made perpendicularly to the joint line (Fig. 6), where the greatest jump of the microhardness occurs at the joint surface. The mechanism of this strengthening involves the dislocation strengthening and, probably, the grain boundary strengthening due to the grain refinement which occurs as a result of the accumulation of severe plastic deformation in this region. With increasing
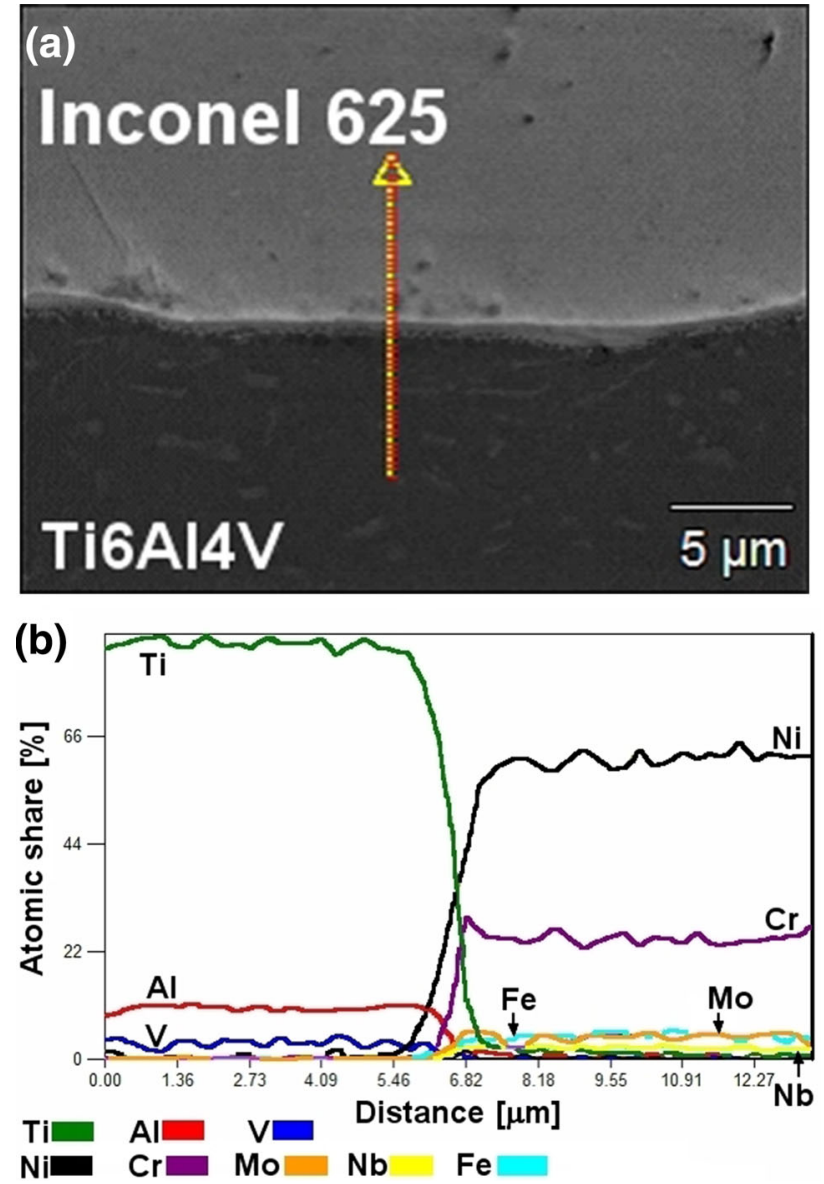

Fig. 5 EDS line analysis of the elements distributions in the joint zone after heat treatment

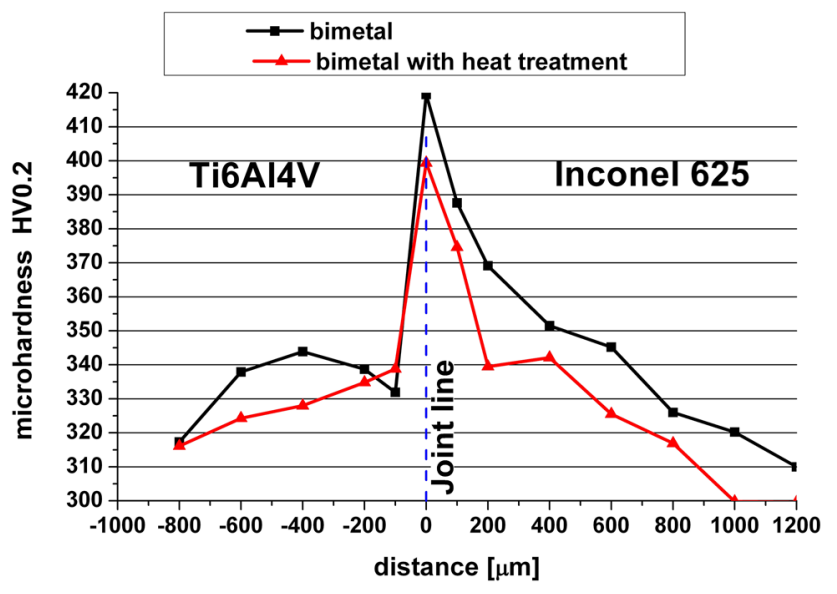

Fig. 6 Microhardness measurements made perpendicularly to the joint line-microhardness distribution as a function of the distance from the joint line

distance from the joint line, the microhardness gradually decreases to reach, beyond the joint zone, the value close to that in the as-received material (Table 2). A similar increase of the microhardness is also reported in other papers (Ref 3, 9, 11).

The results of the microhardness measurements in the asreceived materials and in the bimetals but beyond the joint zone (i.e., Ti6Al4V base and Inconel 625 base) are given in Table 2. 
We can see that beyond the joint zone, the explosive process only resulted in a slight increase of the microhardness.

The HT gave a slight but noticeable and uniform decrease of the microhardness on the entire cross section of the bimetal (Fig. 6) in both the joint zone and beyond it (Fig. 6; Table 2). The diffusion effects observed in the joining zone (Fig. 4) have not led to the formation of a structure with a higher microhardness.

The Ti6A14V/Inconel 625 bimetallic samples were also subjected to three-point bending tests, often reported in the literature (Ref 2-4). The load was applied from the top. The angle achieved during the bending was about $90^{\circ}$. The tests were performed in two opposite positions of the sample: (1) Ti6Al4V-top and (2) Inconel 625-top. The exemplary samples after the bending test are shown in Fig. 7. The exemplary results of the three-point bending test are shown in Fig. 8, where the vertical axis indicates the maximum bending stress, and the horizontal axis indicates the displacement. In Fig. 8, the

Table 2 Microhardness $\mathrm{HV}_{\mathbf{0 . 2}}$ for the as-received materials and for the bimetals in the area beyond the joint line - the average values and the standard deviation (SD) values

\begin{tabular}{lcclll}
\hline & \multicolumn{2}{c}{ Ti6AI4V } & & \multicolumn{2}{c}{ Inconel 625 } \\
\cline { 2 - 3 } \cline { 6 - 6 } Sample & Average & SD & & Average & SD \\
\hline As-received & 325 & 12.3 & & 317 & 16.7 \\
Bimetal & 332 & 9.5 & & 323 & 14.4 \\
Bimetal with HT & 320 & 9.0 & & 304 & 14.3 \\
\hline
\end{tabular}

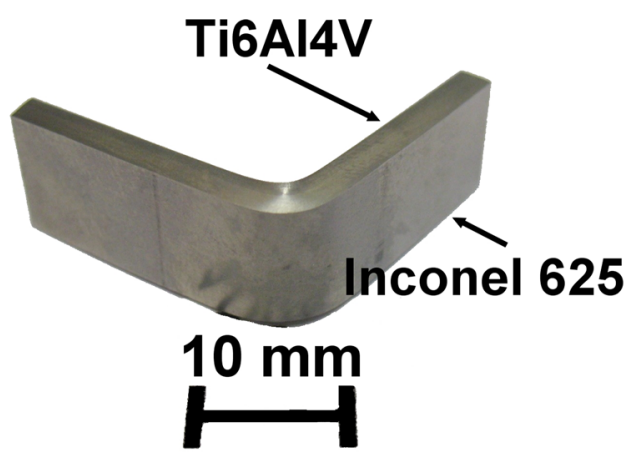

(a)

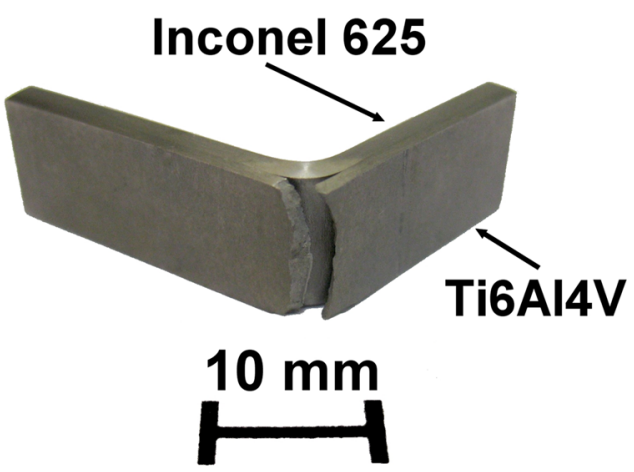

Fig. 7 Appearance of a exemplary Ti6A14V/Inconel 625 bimetallic sample after the bending test: (a) position Ti6A14V-top, (b) position Inconel 625-top maximum values of displacement correspond to the time when the test was stopped.

It has been observed that the HT does not affect significantly the strength of the joint. In the particular position, both the samples (not subjected to HT and heat-treated), exhibited almost the same value of stress. The strength of the joint markedly depended on the position of the sample.

In macroscopic observations of the samples in the Ti6Al4Vtop position (both the no heat-treated and the heat-treated), no cracks, delamination, or chipping can be seen (Fig. 7a). Even though the deformation induced in the samples was severe, none of them failed. These results give evidence of the excellent adhesion of the joined materials. This is confirmed by the stable curve in the diagram of the bending stress (Fig. 8). The diagram shows no sharp changes or peaks, which confirms that there are no cracks and delamination.

However, all the samples tested in the Inconel 625-top position failed during the test, and the Ti6Al4V sheet was separated. The crack occurred at the corner of the sample, where the sample is rounded and the deformation is the more severe (Fig. 7b). The separation can be attributed to the intensive tension applied to the thinner and less ductile Ti6Al4V sheet. The Inconel 625 sheet has not undergone any damage. Beyond the crack region, the two sheets were not

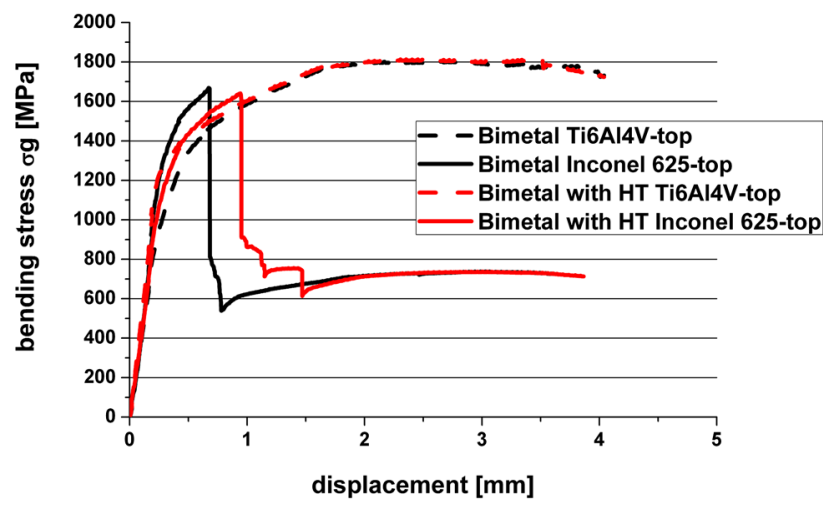

Fig. 8 Exemplary results of the three-point bending test, where the vertical axis indicates the maximum bending stress, and the horizontal axis indicates the displacement

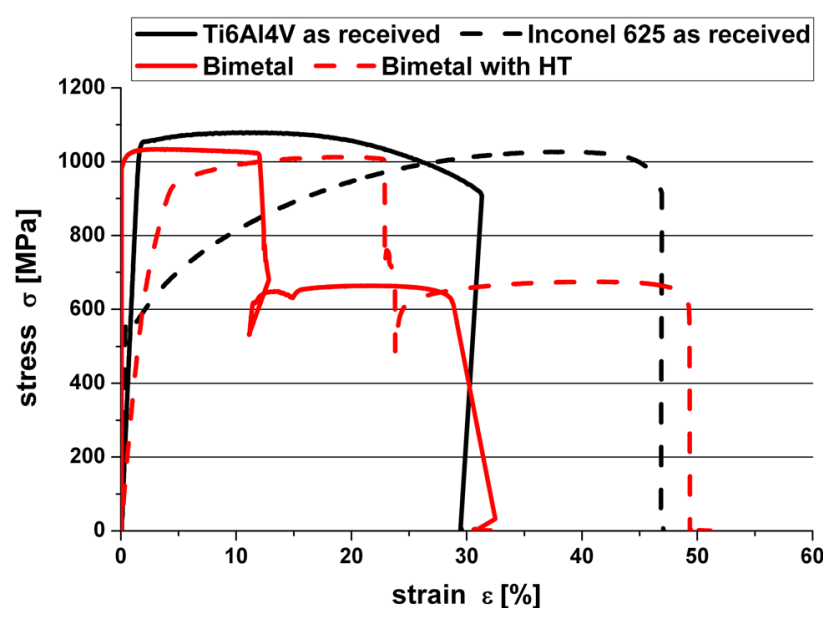

Fig. 9 Exemplary results obtained in the tensile experiments - in the case of bimetal, the first sudden stress decrease was related with crack of Ti6A14V sheet 
Table 3 Mechanical properties of the samples evaluated based on the tensile test

\begin{tabular}{lcccc}
\hline Parameter & $\begin{array}{c}\text { Ti6Al4V } \\
\text { as-receivedTest No. 1/No. 2/SD }\end{array}$ & $\begin{array}{c}\text { Inconel 625 } \\
\text { as-receivedTest No. } \\
\text { 1/No. 2/SD }\end{array}$ & $\begin{array}{c}\text { BimetalTest No. 1/ } \\
\text { No. 2/SD }\end{array}$ & $\begin{array}{c}\text { Bimetal with HTTest } \\
\text { No. 1/No. 2/SD }\end{array}$ \\
\hline YS, MPa & $1054 / 992 / 31$ & $570 / 574 / 2$ & $\ldots$ & $\ldots$ \\
UTS, MPa & $1079 / 1042 / 18.5$ & $1025 / 1027 / 1$ & \\
BS, MPa & $907 / 869 / 19$ & $918 / 913 / 2.5$ & $1032 / 1034 / 1$ & $998 / 1013 / 7.5$ \\
A, \% & $29.9 / 18.3 / 5.8$ & $38.5 / 46.8 / 4.1$ & $1025 / 1015 / 5$ & $975 / 1002 / 13.5$ \\
\end{tabular}

HT: heat treatment, YS: yield stress, UTS: ultimate tensile strength, A: elongation, BS: breaking stress (the ratio of the force recorded at the moment of the appearance of the first crack and the initial surface area of the transverse cross section of the sample), SD: standard deviation

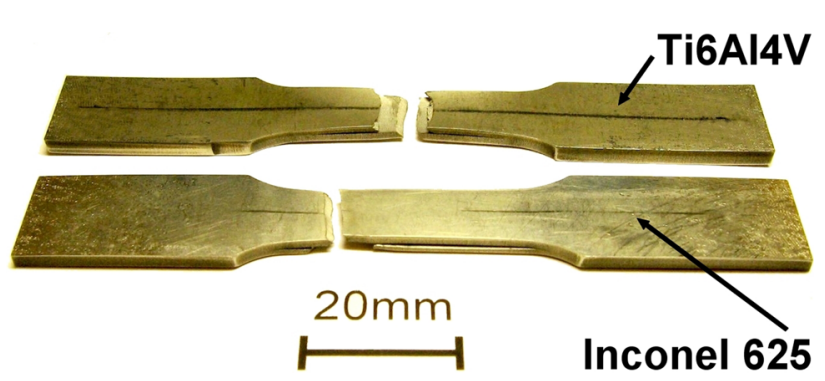

Fig. 10 Exemplary results obtained in the tensile experiments-appearance of the sample with the clear difference in the elongation between the two sheets is visible

disrupted. In the diagram shown in Fig. 8, the disruption is seen as a sudden fall of the bending stress. After the sample failure, the bending test was continued, i.e., the bending force was applied to the Inconel 625 sheet alone, which is reflected in the diagram as a flat and stable fragment of the curve.

Samples were also subjected to the uniaxial tensile test. It is worth noting here that testing bimetals by the tension test has rarely been reported in the literature (Ref 12). The exemplary results obtained in these experiments are shown in Fig. 9 and 10 and in Table 3. During the test all the bimetal samples (without HT and subjected to the HT) failed in the same way i.e., after achieving relatively small deformation, the first to crack was the less ductile Ti6Al4V sheet (the first sudden stress decrease-Fig. 9). Then, the test was continued, because the more ductile Inconel 625 sheet was still tensed alone until its failure (the next sudden stress decrease in Fig. 9). In Fig. 9, where the appearance of both sides of the sample was revealed, the clear difference in the elongation between the two sheets which form the joint is visible.

It was observed that the ductility of the joint was lower than that of its constituent sheets. This can be attributed to the strain hardening which occurred in the joining zone during the explosion and could result in a loss of ductility there and cracking after a short time under tension. Another reason could be the different mechanical properties of joined sheets. The strength of the joint appeared to be comparable with that of the sheets in the as-received state. On the other hand, the breaking stress was higher in the bimetal than in the individual separate sheets in the as-received state (Table 3). This can be attributed to the lower ductility of bimetal and, as a consequence, decohesion at higher stress. The HT of the bimetal increased essentially its ductility (the first sudden stress decrease over $20 \%$ ) with a slight decrease of its strength, which corresponds with the results of the microhardness.

\section{Summary and Conclusions}

In this study, the following materials were tested: (1) raw as-received Ti6Al4V alloy, (2) raw as-received Inconel 625 alloy, (3) Ti6Al4V/Inconel 625 joint, and (4) the Ti6Al4V/ Inconel 625 joint after annealing. Complex examinations consisting of microscopes observations and mechanical properties measurements were made. Using a light microscope and a scanning electron microscope, the microstructure, the joint surface, and elements distribution in the joint zone were analyzed. The mechanical properties were estimated by microhardness measurements, tensile tests, and three-point bending tests.

Using the explosion method it is possible to join a sheet made of Ti6Al4V titanium alloy with a sheet made of the Inconel 625 alloy. The explosive process resulted in a goodquality bimetallic joint and the samples exhibited a good strength and plasticity. These two sheets forming the joint adhere well to one another, which was confirmed by mechanical tests. In the joint zone, the strengthening of the metals was revealed by the microhardness increasement. Moreover, based on the microhardness measurement of the joint after annealing, it can be concluded that the recrystallization process in the joining zone did not occur. The HT applied to the joint did not affect its adhesion and strength, but increased its ductility. Besides, the treatment did not lead to the formation of a strength structure with a higher microhardness. The results of three-point bending tests revealed a good adhesion of the sheets. The cracks only appeared in one position of the samples as a result of the effect of the severe extension of the thin and less ductile Ti6Al4V sheet.

The joint surface had a correct wavy shape. Using a higher magnification, the thin diffusion layer was revealed. Nevertheless, in the joint line, SEM-EDS results showed the clear change of the chemical composition. In both the joints (without HT and subjected to the HT), a sharp transition between the two materials was observed, whereas the diffusion was not observed. In contrast to the annealing and plastic deformation induced during the explosive joining process, the thin diffusion layer did not influence the mechanical properties of the joint. 


\section{Acknowledgements:}

Financial support of Project "Modern material technologies in aerospace industry," Nr POIG.01.01.02-00-015/08-00 is gratefully acknowledged.

\section{Open Access}

This article is distributed under the terms of the Creative Commons Attribution 4.0 International License (http://creativecommons. org/licenses/by/4.0/), which permits unrestricted use, distribution, and reproduction in any medium, provided you give appropriate credit to the original author(s) and the source, provide a link to the Creative Commons license, and indicate if changes were made.

\section{References}

1. F. Findik, Recent Developments in Explosive Welding, Mater. Des., 2011, 32, p 1081-1093 (in English)

2. N. Kahraman, B. Gulenc, and F. Findik, Joining of Titanium/Stainless Steel by Explosive Welding and Effect on Interface, J. Mater. Process. Technol., 2005, 169, p 127-133 (in English)

3. M. Acarer, B. Gulenc, and F. Findik, The Influence of Some Factors on Steel/Steel Bonding Quality on Their Characteristics of Explosive Welding Joints, J. Mater. Sci., 2004, 39(21), p 6457-6466 (in English)
4. N. Kahraman, B. Gulenc, and F. Findik, Corrosion and MechanicalMicro Structural Aspects of Dissimilar Joints of Ti-6Al-4V and Al Plates, Int. J. Impact Eng., 2007, 34(8), p 1423-1432 (in English)

5. S. A. A. Mousavi, S. T. S. Al-Hassani, A. G. Atkins, Bond Strength of Explosively Welded Specimens, Mater. Des., 2008, 29(7), p. 1334 1352 (in English)

6. B. Wronka, Testing of Explosive Welding and Welded Joints: Joint Mechanism and Properties of Explosive Welded Joints, J. Mater. Sci., 2010, 45(15), p. 4078-4083 (in English)

7. A. Nobili, T. Masri, M. C. Lafont, Recent Developments in Characterization of a Titanium-Steel Explosion Bond Interface, Proceedings of Reactive Metals in Corrosive Applications Conference, Eds (Albany), Wah Chang; 1999, p 89-98 (in English)

8. P. Manikandan, K. Hokamoto, M. Fujita, K. Raghukandan, and R. Tomoshige, Control of Energetic Conditions by Employing Interlayer of Different Thickness for Explosive Welding of Ti/304 Stainless Steel, J. Mater. Process. Technol., 2008, 195, p 232-240 (in English)

9. N. Kahraman and B. Gulenc, Microstructural and Mechanical Properties of $\mathrm{Cu}-\mathrm{Ti}$ Plates Bonded Through Explosive Welding Process, $J$. Mater. Process. Technol., 2005, 69, p 67-71 (in English)

10. N. Kahraman and B. Gulenc, Metallurgical and Corrosion Properties of Explosively Welded Ti6A14V/ Low Carbon Steel Clad", J. Mater. Sci. Technol., 2005, 21(5), p 743-747 (in English)

11. K. Topolski, P. Wieciński, Z. Szulc, A. Gałka, and H. Garbacz, Development in Characterization of Explosively Joined Ti/Ni Bimetals, Mater. Des., 2014, 63, p 479-487 (in English)

12. H. Zhao, P. Li, Y. Zhou, Z. Huang, and H. Wang, Study on the Technology of Explosive Welding Incoloy 800-SS304, JMEPEG, 2011, 20, p 911-917 (in English) 